\title{
I I 8 Manganese guided cellular MRI enables evaluation of human stromal cell viability
}

\author{
Mayumi Yamada*1, Paul T Gurney ${ }^{1}$, William Stein ${ }^{1}$, Pratima Kundu' ${ }^{1}$, \\ Alan Smith ${ }^{2}$, Robert C Robbins ${ }^{1}$ and Phillip C Yang ${ }^{1}$
}

Address: ${ }^{1}$ Stanford University, Stanford, CA, USA and ${ }^{2}$ Cognate Bio Services, Inc., Sunnyvale, CA, USA

* Corresponding author

from I th Annual SCMR Scientific Sessions

Los Angeles, CA, USA. I-3 February 2008

Published: 22 October 2008

Journal of Cardiovascular Magnetic Resonance 2008, I0(SuppI I):A19 doi:I0.I I86/I532-429X-I0-SI-AI9

This abstract is available from: http://jcmr-online.com/content/I0/SI/AI9

(c) 2008 Yamada et al; licensee BioMed Central Ltd.

\section{Background}

Human stromal cells (hSC) have demonstrated restorative capabilities of the injured myocardium. Although iron oxide particles have demonstrated in vivo MRI cell tracking, fundamental biological properties including cell viability of transplanted cells are not evaluated. We tested the hypothesis that manganese chloride $\left(\mathrm{MnCl}_{2}\right)$ will enable MRI assessment of hSC viability.

\section{Methods}

Human stromal cells (Cognate, Sunnyvale, CA) were trypsinized and labeled with different concentrations of $\mathrm{MnCl}_{2}$ in normal saline and incubated for $0.5-1.0$ hour at $37^{\circ} \mathrm{C}$ and $5 \% \mathrm{CO}_{2}$. Biological properties of hSC were monitored by modulating the activity of calcium channels using verapamil (calcium channel antagonist). $\mathrm{T}_{1}$ and $\mathrm{T}_{2}$ mapping was performed at $0.01-3.00 \mathrm{mM}$ of $\mathrm{MnCl}_{2}$ solution with $1.5 \mathrm{~T}$ GE Excite whole-body MRI scanner (Signa, GE Medical Systems, Milwaukee, WI) with a 5-inch receive only surface coil. For T1 measurements, spin echo (SE) inversion recovery sequence (FOV $12 \mathrm{~cm}$, matrix size of $128 \times 128$, TR $3000 \mathrm{~ms}$ and TE 50-2200 ms at $300 \mathrm{~ms}$ steps) were used. We made T2 measurements using SE sequence (FOV $12 \mathrm{~cm}$, matrix size of $128 \times 128$, TR 2500 $\mathrm{ms}$ and TE $10-80 \mathrm{~ms}$ at $10 \mathrm{~ms}$ steps). Then the data were analyzed to extract T1 and T2 values through nonlinear least-square fits to the SE inversion recovery and the SE decay curve respectively. In vitro cellular MRI was performed using optimized SE sequence (FOV $12 \mathrm{~cm}$, matrix size of $256 \times 256$, TR $800 \mathrm{~ms}$ and TE $3.4 \mathrm{~ms})$. Modulation of hSC calcium channel activity by verapamil was assessed by measuring changes in signal intensity.

\section{Results}

In vitro assessment of cell viability was confirmed by increased signal intensity (SI) due to the T1-shortening effects of intracellular $\mathrm{MnCl}_{2}$ accumulation. Viable hSC generated increased T1-shortening effects with increasing extracellular concentrations of $\mathrm{MnCl}_{2}$. Calclium-channel mediated biological activity of hSC was confirmed by the significant $40 \%$ reduction of SI ( $858 \pm 50$ vs. $524 \pm 48, \mathrm{p}$

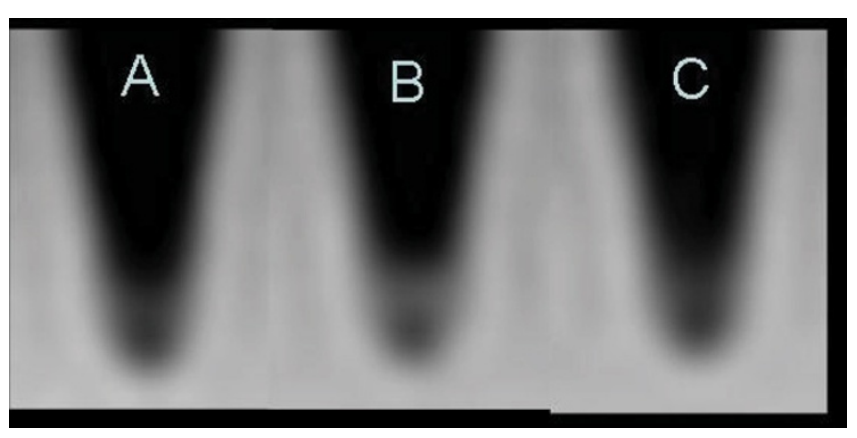

Figure I

MRI of the hSC in different Mn concentration (A) control (hSCs in normal saline), (B) $0.10 \mathrm{mM} \mathrm{Mn,} \mathrm{(C)} 0.10 \mathrm{mM}$ with $250 \mu \mathrm{M}$ Verapamil. Manganese chloride can demonstrate the potential to detect cellular viability and biological property, hence it can be used as a non invasive biological evaluation of transplanted human stromal cells within injured myocardium. 


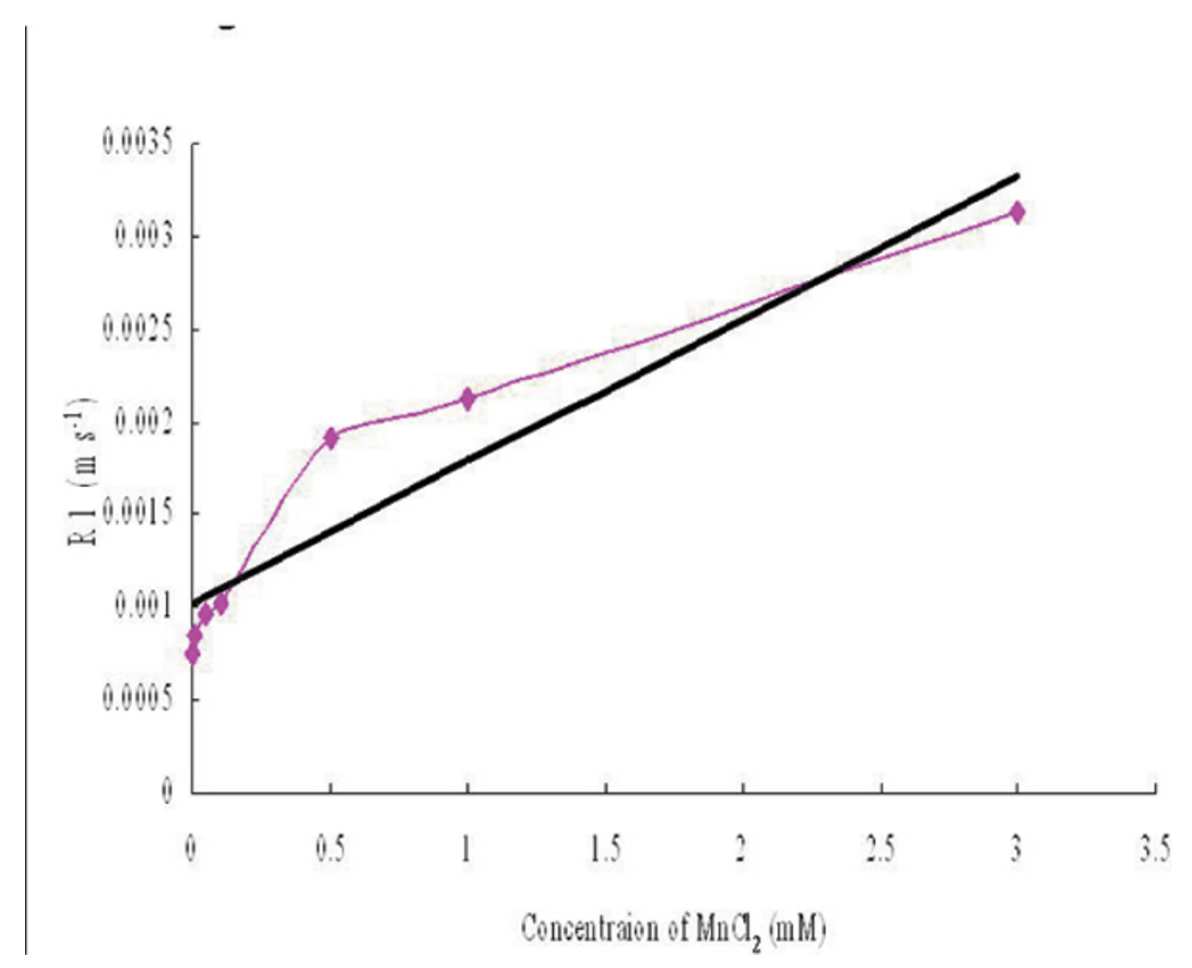

\section{Figure 2}

Relaxtivities of human stromal cells $(n=3)$.

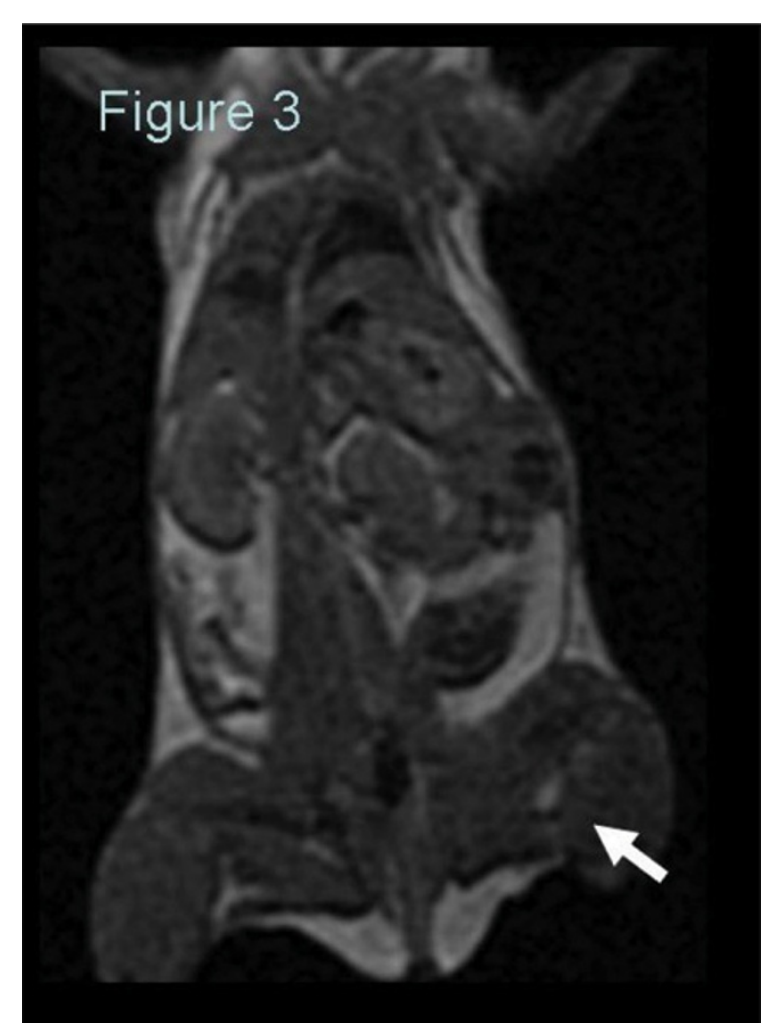

Figure 3
$<0.05, \mathrm{n}=3$ ) when verapamil was co-administered with $0.10 \mathrm{mM} \mathrm{MnCl}_{2}$ (Figure 1). Furthermore, T1 and T2 relaxation times of $\mathrm{Mn}$ labeled hSC have been measured (Figure 2). Finally, in vivo MRI demonstrated viability of hSC following transplantation into mouse right hindlimb as shown in figure 3 (white arrow).

\section{Conclusion}

$\mathrm{MnCl}_{2}$-guided cellular MRI demonstrates the potential to detect calcium-channel mediated biology of transplanted hSC including cell viability. This technique may enable MRI-guided biological evaluation of transplanted cells. 